\title{
Real and nominal stochastic convergence: Are the new EU members ready to join the Euro zone?
}

\author{
Ali M. Kutan ${ }^{\mathrm{a}, \mathrm{b}, \mathrm{c}, \mathrm{d}, *}$, Taner M. Yigit ${ }^{\mathrm{e}}$ \\ a Economics and Finance Department, Southern Illinois University Edwardsville, \\ Edwardsville, IL 62026-1102, USA \\ b The Center for European Integration Studies (ZEI), 53113 Bonn, Germany \\ c The William Davidson Institute (WDI), Ann Arbor, MI 48109-1234, USA \\ d The Emerging Markets Group (EMG), London EC1Y 8TZ, UK \\ e Bilkent University, Bilkent, 06800 Ankara, Turkey
}

Received 28 June 2004; revised 25 February 2005

Available online 18 April 2005

\begin{abstract}
Kutan, Ali M., and Yigit, Taner M.--Real and nominal stochastic convergence: Are the new EU members ready to join the Euro zone?

A key requirement for the new members to join the European Economic and Monetary Union (EMU) is real and financial convergence to European Union (EU) levels. This paper expands the analysis in [Kočenda, E., Macroeconomic convergence in transition economies, Journal of Comparative Economics 29 (2001) 1-23] and [Kutan, A., Yigit, T., Nominal and real stochastic convergence of transition economies, Journal of Comparative Economics 32 (2004) 23-36] by investigating the convergence of the new EU members to these standards. Using panel unit root techniques, we find strong evidence of real stochastic convergence for all new members, which indicates that they adjust to Euro-area output shocks. However, the degree of nominal convergence is idiosyncratic. The Baltic states exhibit the strongest monetary policy and price-level convergence, suggesting that they are ready to adopt the Euro. However, Central and East European countries should address the reasons for their lack of convergence before adopting the Euro. Journal of Comparative Economics 33 (2) (2005) 387-400. Economics and Finance Department, Southern Illinois University Edwardsville, Ed-
\end{abstract}

\footnotetext{
* Corresponding author.

E-mail addresses: akutan@ siue.edu (A.M. Kutan), tyigit@ bilkent.edu.tr (T.M. Yigit).
} 
wardsville, IL 62026-1102, USA; The Center for European Integration Studies (ZEI), 53113 Bonn, Germany; The William Davidson Institute (WDI), Ann Arbor, MI 48109-1234, USA; The Emerging Markets Group (EMG), London EC1Y 8TZ, UK; Bilkent University, Bilkent, 06800 Ankara, Turkey. (C) 2005 Association for Comparative Economic Studies. Published by Elsevier Inc. All rights reserved.

\section{Introduction}

A key goal of transition economies in Central and Eastern Europe (CEE) is to join the European Economic and Monetary Union (EMU) after their admission to the European Union (EU). To join the EMU and to adopt the Euro, the Maastricht criteria for full EMU membership must be met; these require convergence in inflation, interest rates, exchange rates, and government deficit and debt towards the EU averages. The next stage of monetary integration is to join the Exchange Rate Mechanism (ERM II) of the EMU. According to the European Central Bank, nominal and real convergence within the ERM II framework should be achieved before the adoption of the Euro (European Central Bank, 2002). In this paper, we test for such convergence in the ten recent members that joined the EU in May 2004. Of these ten countries, eight are transition economies, namely the Czech Republic, Estonia, Hungary, Latvia, Lithuania, Poland, the Slovak Republic, and Slovenia. We refer to these eight countries as the CEE8; to consider separately the performance of the Baltic states, i.e., Estonia, Latvia and Lithuania, we divide the CEE8 into two groups, namely the Baltic states and the remaining five countries, denoted the CEE5. Cyprus and Malta are the other two new members. Our findings have important implications for the choice of an exchange rate regime and the time of entry to the Euro zone by the new members before they consider a formal and permanent peg to the Euro.

Babetskii et al. (2004), Boone and Maurel (1998, 1999), Backè et al. (2003), Brada and Kutan (2001), Fidrmuc and Korhonen (2003), and Richards and Tersman (1996) investigate the convergence of the candidate countries to EU standards. Most of these papers do not provide comprehensive evidence in terms of country coverage and they rely on relatively small time-series data sets. Some studies focus on nominal convergence, while others examine only real convergence to EU standards. Babetskii et al. (2004) analyze both nominal and real convergence of the CEE8, in addition to the experiences of Ireland, Portugal, and Spain. Using the Kalman filter, these authors study the time-varying correlation of demand and supply shocks between these countries and the Euro area. They find significant convergence of demand shocks, but divergence of supply shocks. In a similar study, Fidrmuc and Korhonen (2003) find that the correlation of supply shocks of selected CEE countries with the Euro area is higher than those of demand shocks. Using different time-series methodologies, Boone and Maurel $(1998,1999)$ find that business cycles in CEE countries are similar to those in Germany and the Euro area, suggesting that full EMU membership for CEE countries would be fruitful. Overall, the evidence on convergence of the new members to the Euro-area standards is mixed. 
In this paper, we examine both nominal and real economic convergence to EU standards for all ten recently admitted members. Kočenda (2001) and Kutan and Yigit (2004) analyze real and nominal convergence within transition economies, but not to EU standards. Employing panel unit root tests, these papers examine real convergence based on industrial output and monetary variables, such as the producer price index (PPI), the consumer price index (CPI), narrow money (M1), and both nominal and real interest spreads. Using monthly data from 1991 to 1998, Kočenda (2001) finds considerable real and monetary convergence. The first-round EU candidates, which are now new EU members, exhibit relatively high degrees of convergence. The Baltic states yield the highest degree of convergence, due partly to their common exchange rate regimes and their lack of independent monetary policy. Considering a more stable, post-1993 period and adopting a panel estimation approach, Kutan and Yigit (2004) show that convergence results are sensitive to the choice of econometric methodology and that nominal and real convergence is not as great as Kočenda's results indicate.

In this paper, we extend the earlier work in several directions. First, our sample period is longer, covering January 1993 through December 2003 period, so that our inferences on convergence are more reliable. Second, we use a set of confirmatory heterogeneous panel approaches that allow us not only to test for convergence more reliably than is possible with only time-series data, but also to maintain an assumption of cross-country differences. Third, we address the issue of convergence of the new member states with respect to both the founding and the newer members of the Euro zone. Germany and Greece are taken to represent a core member that is the most important trading partner in the region and a peripheral country, respectively. Finally, we investigate individual country performance by utilizing a series-specific panel technique. This panel approach allows country-specific inferences without sacrificing the increased power associated with the panel dimension.

\section{Methodology}

In the past decade, several empirical techniques to test for convergence have been developed based on the neoclassical growth model. One branch of the literature consists of studies using time series methodology to test the convergence hypothesis. Based mainly on unit root tests, these papers capture the persistence of shocks relative to per capita incomes. Barro and Sala-i-Martin (1992), Friedman (1992), and Quah (1993) concentrate on notions of $\beta$ convergence for which poor countries grow faster than rich ones and $\sigma$ convergence for which income variance between poor and rich countries is diminishing. In contrast, our analysis concentrates on conditional stochastic convergence, which does not require each country to converge to the same steady state. This notion of convergence is applicable when per capita income disparities between countries follow a mean-stationary (MS) process, i.e., relative per capita income shocks lead to only transitory deviations from any tendency toward convergence. For the ten recent members of the EU, we use stochastic convergence tests to determine whether a country has satisfied the membership requirements successfully by reforming its institutions to insure that convergence is permanent. If the necessary mechanisms are not in place, a deviation from the trend of the core EU 
countries will result in lengthy periods of adjustment or no adjustment at all. Hence, this notion of convergence is more important for our purposes than those that measure catching up, i.e., $\beta$ and $\sigma$ convergence, because it tests the significance of institutional reforms and their durability.

Recently, panel unit root tests ${ }^{1}$ have been adopted to address the low explanatory power of univariate tests; these techniques increase the power of the test for convergence by the square root of the cross sectional units. Panel data estimation techniques also avoid the criticisms directed at cross-sectional and time-series tests of convergence by Bernard and Durlauf (1996), in particular, their tendency to reject of the null of no convergence too frequently and their inadequacy in dealing with the transition toward steady states. ${ }^{2}$ In this paper, we use two different types of tests; the first focuses on the convergence of the whole group and the second concentrates on the performance of the individual countries. For the group tests, we use tests presented in Hadri (2000) and Im et al. (2003), hereafter IPS, because of their superior size and power properties, in addition to their allowance for heterogeneity of cross-sectional units within the panel. We supplement these results by the series-specific panel unit root test developed by Breuer et al. (2002), to draw implications for individual countries as well as for the whole group.

The IPS test improves the power of the univariate Augmented Dickey-Fuller (ADF) procedures by

$$
\Delta\left(y_{i, t}-\bar{y}_{t}\right)=\rho_{i}\left(y_{i, t-1}-\bar{y}_{t-1}\right)+\sum_{k=1}^{p} \phi_{i, k} \Delta\left(y_{i, t-k}-\bar{y}_{t-k}\right)+Z_{i t}^{\prime} \gamma_{i}+u_{i, t},
$$

where $y_{i, t}-\bar{y}_{t}$ is the deviation of $i=1, \ldots, N$ countries at time $t$ from the benchmark economy and $Z_{i t}$ is the deterministic component. We assume fixed effects for $Z_{i t}$ to allow for heterogeneity in the growth rates. ${ }^{3}$ Their method pools $N$ separate independent ADF regressions, in which values of $\rho_{i}$ less than 1 indicate that deviation from the benchmark is decreasing with time, thus, convergence. To test the null hypothesis of unit root, i.e., $\rho_{i}=0$, which implies no convergence for all $i$ against the alternative hypothesis that $\rho_{i}<0$ for at least one $i$, the limiting distribution for the $t$-statistic is given by

$$
\sqrt{N} \frac{\left(\bar{t}_{\mathrm{ADF}}-\mu_{\mathrm{ADF}}\right)}{\sqrt{\sigma_{\mathrm{ADF}}^{2}}} \rightarrow N(0,1),
$$

where the moments $\mu_{\mathrm{ADF}}$ and $\sigma_{\mathrm{ADF}}^{2}$ are obtained from Monte Carlo simulations and $\bar{t}_{\mathrm{ADF}}$ is the average estimated ADF $t$-statistic from the sample. Simulations demonstrate that

\footnotetext{
1 Quah (1992), Levin et al. (2002), Maddala and Wu (1999), Hadri (2000), Breuer et al. (2002), and Im et al. (2003) are examples of these tests.

2 Bernard and Durlauf (1996) show that cross-sectional tests reject the null of no convergence incorrectly due to the existence of multiple long-run equilibria. They also demonstrate that time-series tests avoid this problem of spurious rejection but are prone to other problems when applied to countries in transition because they assume that sample moments approximate accurately the limiting moments for the data.

3 The deterministic component can also take the following forms: (1) $Z_{i t}$ is zero, which implies that countries share same steady states; (2) $Z_{i t}$ is equal to one and $\gamma$ is the same for all $i$ so that all countries share the same growth rate; (3) $Z_{i t}$ includes fixed effects plus a time trend, i.e., there is a changing disparity between the growth rates.
} 
the power of the tests should increase by $\sqrt{N}$ compared with single-country models. The IPS technique requires the error term to be individually and identically distributed. If this assumption is violated and the residuals are correlated contemporaneously, Maddala and $\mathrm{Wu}$ (1999) and Strauss and Yigit (2003) show that this technique suffers from significant size distortions that do not disappear with simple demeaning. Therefore, we make size adjustments by deriving new critical values for the IPS test.

In addition, we consider a test that has stationarity, i.e., convergence, rather than a unit root as the null hypothesis. Since panel tests in which the null hypothesis of unit roots are not very powerful against relevant alternative hypotheses, i.e., slow rates of convergence, we use the stationarity test to check for real and nominal convergence suggested by Hadri (1999, 2000). Beginning with the following model:

$$
\begin{gathered}
y_{i t}=r_{i t}+\varepsilon_{i t} \quad \text { or } \quad y_{i t}=r_{i t}+\beta_{i} t+\varepsilon_{i t} \\
\text { and } r_{i t}=r_{i t-1}+u_{i t}
\end{gathered}
$$

and testing the null hypothesis that all variances of $u_{i t}$, i.e., $\sigma_{u i}^{2}$, are zero versus the alternative hypothesis that $\sigma_{u i}^{2}>0$ for some $i$, the author demonstrates that the normalized one-sided statistic is given by

$$
L M_{j}=\frac{1}{N} \sum_{i=1}^{N}\left(\frac{\frac{1}{T^{2}} \sum_{t=1}^{T} S_{i t}}{\hat{\sigma}_{\varepsilon i}^{2}}\right),
$$

where $S_{i t}$ is the partial sum of the residuals so that $S_{i t}=\sum_{j=1}^{t} \hat{\varepsilon}_{i j}$ for $j=\mu$, $\tau$, i.e., mean and trend stationarity. In addition, the $L M$ statistic is distributed asymptotically normal as

$$
\frac{\sqrt{N}\left(L M_{j}-\mu_{j}\right)}{\sigma_{j}},
$$

with $\mu_{j}$ and $\sigma_{j}$ as the asymptotic mean and standard deviation of the $L M$ statistic. Simulations indicate that the size and power of this test, especially when $T$ is above 50, are good. We use Monte Carlo simulations to derive critical values specific to the cross-correlation structure of the sample countries. In summary, the Hadri test shows that the deviations from the benchmark economy are not very large, i.e., $S_{i t}$ is relatively small.

Model specification is important for these techniques because the issue of incidental trends, i.e., a situation in which only some cross-sectional units have a deterministic time trend, is not resolved completely in the panel unit-root literature. Therefore, we take a conservative approach by not testing for trend-stationarity in the IPS tests, but using them only for the Hadri tests. The addition of a trend in the unit-root null hypothesis and the exclusion of a trend in the stationarity null hypothesis lead to size distortions in both tests. A combination of these two tests with differing null hypotheses is a complementary approach because one test hypothesizes that all the series are not stationary with the alternative being that some are, while the other hypothesizes that all series are stationary with the alternative being that some are not. Therefore, if we have a mixture of convergent and non-convergent countries, both tests should result in the rejection of their respective null hypotheses. In essence, the combined approach establishes whether any one of the countries in the group is converging to the chosen benchmark country. Despite the high power of these tests, they 
do not indicate how many or which of these countries are converging. To draw more informative conclusions and policy prescriptions, we need information on the performance of the individual countries in the panel. By using Seemingly Unrelated Regression (SUR), Breuer et al. (2002) improve on the power of univariate time series tests without sacrificing as much series-specific information.

In their combined SUR-ADF method, Breuer et al. start with a specification similar to Eq. (1) and test the following $N$ null and alternative hypotheses individually:

$$
\begin{array}{clccl}
H_{0}^{1}: & \rho_{1}=0 & \text { vs. } & H_{A}^{1}: & \rho_{1}<0, \\
\vdots & \vdots & & \vdots \\
H_{0}^{N}: & \rho_{N}=0 & \text { vs. } & H_{A}^{N}: & \rho_{N}<0 .
\end{array}
$$

The authors use the cross correlation between the members of the panel, which is actually a disadvantage in the other panel unit-root methods and requires correction of critical values using Monte Carlo simulations. In fact, the high cross correlation that causes considerable problems for panel unit-root tests increases the power of SUR-ADF method compared to single-equation methods. The flexible nature of the Breuer et al. panel estimation also allows for varying orders of autocorrelation for the panel members. In addition to these advantages, we choose this test because it allows us to draw conclusions on the stationarity, or convergence, of individual series in the panel. The drawback with this series-specific information is the need to generate panel-specific critical values for each sample due to the uniqueness of the correlation matrices in differing panels. ${ }^{4}$ Drawing Monte Carlo simulations for a variety of scenarios, Breuer et al. derive significant power improvements over single-equation methods, especially when correlation between the panel members is high.

\section{Data and results}

We use data from the first month of 1993 to the last month of 2004 to test for the convergence in annual growth rates of monthly industrial production, prices measured both by the PPI and CPI, and nominal interest rate spreads for the ten recently admitted EU countries. ${ }^{5}$ Germany is taken as the benchmark to represent core EU standards, and Greece, a more recent member, is taken to check the robustness of our results applied to a peripheral member of the Euro zone. The data are obtained from International Financial Statistics (IFS); the breaks in the IFS datasets are supplemented by government websites for the relevant countries. ${ }^{6}$ Descriptive statistics are reported in Table 1.

Following previous studies, we measure real convergence by industrial production. Our analysis of nominal convergence starts with tests for monetary policy convergence.

\footnotetext{
${ }^{4}$ We are grateful to Jan Breuer and Myles Wallace for providing us with their simulation routines and detailed instructions.

5 Spread is measured by the difference between lending and deposit rates.

6 If a break occurs in the IFS dataset, we refer to country-specific information and use the growth rates of these variables. A more detailed description of our method is found in Appendix A.
} 
Table 1

Descriptive statistics

\begin{tabular}{|c|c|c|c|c|c|c|c|c|}
\hline & \multicolumn{2}{|c|}{ Ind. prod. (growth) } & \multicolumn{2}{|c|}{ CPI (\% change) } & \multicolumn{2}{|l|}{ PPI } & \multicolumn{2}{|c|}{ Spread (levels) } \\
\hline & Mean & Std. dev. & Mean & Std. dev. & Mean & Std. dev. & Mean & Std. dev \\
\hline Cyprus & 1.02 & 6.08 & 3.16 & 1.26 & 2.60 & 2.19 & 2.47 & 0.75 \\
\hline Czech Rep. & 3.25 & 5.53 & 5.76 & 3.68 & 3.04 & 2.56 & 5.14 & 0.98 \\
\hline Estonia & 6.50 & 7.87 & 17.77 & 24.88 & 6.39 & 7.65 & 7.51 & 4.67 \\
\hline Germany & 1.05 & 4.19 & 1.76 & 1.02 & 0.78 & 1.67 & 6.70 & 0.44 \\
\hline Greece & 1.34 & 3.66 & 6.04 & 3.48 & 5.04 & 3.20 & 6.90 & 1.67 \\
\hline Hungary & 8.05 & 6.43 & 13.75 & 6.69 & 10.86 & 7.97 & 5.00 & 2.37 \\
\hline Latvia & 7.29 & 16.27 & 15.18 & 23.28 & 3.65 & 5.22 & 12.04 & 10.28 \\
\hline Lithuania & 3.38 & 19.93 & 22.40 & 42.45 & 24.91 & 53.50 & 7.05 & 5.08 \\
\hline Malta & NA & NA & 2.72 & 1.33 & NA & NA & 2.98 & 0.77 \\
\hline Poland & 6.60 & 5.43 & 13.92 & 10.33 & 11.49 & 9.60 & 7.06 & 1.71 \\
\hline Slovak Rep. & 4.86 & 4.93 & 8.01 & 3.21 & 5.93 & 3.25 & 5.35 & 1.64 \\
\hline Slovenia & 2.67 & 3.88 & 10.95 & 7.50 & 8.42 & 6.54 & 7.28 & 3.43 \\
\hline
\end{tabular}

Notes: 1. NA means data are not available. 2. All values are in percentages, except indicated otherwise.

Although some studies use monetary aggregates, e.g., Brada and Kutan (2001), we use interest rate spreads to measure monetary convergence because changes in nominal lending and deposit rates affect demand and time deposits directly and, thus, the composition of the money supply. Hence, changes in monetary aggregates reflect policy outcomes more than the actual implementation of the policy. To measure price level convergence, we use the CPI and PPI indexes because together they represent monetary policy outcomes and the trade linkages between the countries. Shocks to producer prices may be attributable more to the tradables sector, while changes in consumer prices reflect both developments in nontradables sectors and fiscal shocks. The Balassa-Samuelson effects are also reflected in these price indexes. Therefore, monetary policy shocks should be represented largely in interest rate spreads. ${ }^{7}$

Table 2 reports the convergence results using the IPS method, including the progress made by the candidate countries in converging to the economic standards of Germany and Greece. We generate new critical values using Monte Carlo simulations to correct for the size distortions that arise due to the cross-correlation between the candidate countries, reported in Table 2 as $\mu$ and $\sigma^{2}$. We use the correlation matrix of the sample countries and 5000 iterations to derive the critical values for the mean and variance of the IPS $\bar{t}$ statistic. Then we use these critical values to derive the $z$-statistic of the average. The coefficients for industrial production indicate significant real convergence. The coefficients for inflation measured both by the CPI and PPI indicate strong price-level convergence. We also find significant convergence in monetary policy, measured by the coefficients on interest rate spreads. Overall, the IPS results indicate significant nominal and real convergence for most of the countries.

\footnotetext{
7 The interest-spread measure is more representative of the efficiency of the financial markets than the size of monetary aggregates. The lower is the spread the more efficient is the financial system. Therefore, our results can be interpreted as tests of the convergence of the efficiency of financial systems rather than in the size of monetary aggregates.
} 
Table 2

Convergence results of IPS method (convergence rates, $1+\rho_{i}$, are reported)

\begin{tabular}{|c|c|c|c|c|c|c|c|c|}
\hline & \multicolumn{4}{|c|}{ Germany } & \multicolumn{4}{|c|}{ Greece } \\
\hline & $\begin{array}{l}\text { Industrial } \\
\text { production }\end{array}$ & $\begin{array}{l}\text { CPI } \\
\text { inflation }\end{array}$ & $\begin{array}{l}\text { PPI } \\
\text { inflation }\end{array}$ & Spread & $\begin{array}{l}\text { Industrial } \\
\text { production }\end{array}$ & $\begin{array}{l}\text { CPI } \\
\text { inflation }\end{array}$ & $\begin{array}{l}\text { PPI } \\
\text { inflation }\end{array}$ & Spread \\
\hline \multirow[t]{2}{*}{ Cyprus } & 0.70 & 0.75 & 0.79 & 0.90 & 0.68 & 0.85 & 0.84 & 0.96 \\
\hline & $(-3.05)$ & $(-3.10)$ & $(-3.89)$ & $(-2.44)$ & $(-3.28)$ & $(-2.51)$ & $(-3.63)$ & $(-1.46)$ \\
\hline \multirow[t]{2}{*}{ Czech Rep. } & 0.83 & 0.90 & 0.90 & 0.85 & 0.76 & 0.93 & 0.90 & 0.94 \\
\hline & $(-2.11)$ & $(-3.08)$ & $(-2.99)$ & $(-2.47)$ & $(-2.83)$ & $(-2.46)$ & $(-2.64)$ & $(-1.45)$ \\
\hline \multirow[t]{2}{*}{ Estonia } & 0.76 & 0.92 & 0.92 & 0.73 & 0.80 & 0.90 & 0.88 & 0.85 \\
\hline & $(-2.70)$ & $(-3.64)$ & $(-2.63)$ & $(-3.13)$ & $(-2.58)$ & $(-4.06)$ & $(-2.93)$ & $(-2.26)$ \\
\hline \multirow[t]{2}{*}{ Hungary } & 0.60 & 0.96 & 0.97 & 0.79 & 0.60 & 0.95 & 0.95 & 0.93 \\
\hline & $(-3.66)$ & $(-2.31)$ & $(-1.86)$ & $(-4.18)$ & $(-3.79)$ & $(-2.61)$ & $(-2.20)$ & $(-2.52)$ \\
\hline \multirow[t]{2}{*}{ Latvia } & 0.81 & 0.80 & 0.96 & 0.54 & 0.81 & 0.76 & 0.96 & 0.64 \\
\hline & $(-3.41)$ & $(-9.57)$ & $(-1.99)$ & $(-5.50)$ & $(-3.25)$ & $(-10.52)$ & $(-1.39)$ & $(-4.90)$ \\
\hline \multirow[t]{2}{*}{ Lithuania } & 0.83 & 0.88 & 0.94 & 0.67 & 0.82 & 0.86 & 0.95 & 0.66 \\
\hline & $(-2.76)$ & $(-6.62)$ & $(-5.57)$ & $(-3.85)$ & $(-2.92)$ & $(-7.05)$ & $(-4.38)$ & $(-4.06)$ \\
\hline \multirow[t]{2}{*}{ Malta } & NA & 0.72 & NA & 0.92 & NA & 0.87 & NA & 0.80 \\
\hline & & $(-4.19)$ & & $(-1.48)$ & & $(-3.46)$ & & $(-2.53)$ \\
\hline \multirow[t]{2}{*}{ Poland } & 0.81 & 0.93 & 0.97 & 0.86 & 0.80 & 0.89 & 0.92 & 0.90 \\
\hline & $(-2.66)$ & $(-1.89)$ & $(-0.96)$ & $(-2.64)$ & $(-2.64)$ & $(-2.68)$ & $(-2.15)$ & $(-2.38)$ \\
\hline \multirow{2}{*}{ Slovak Rep. } & 0.84 & 0.92 & 0.81 & 0.82 & 0.70 & 0.93 & 0.72 & 0.81 \\
\hline & $(-2.36)$ & $(-2.24)$ & $(-2.67)$ & $(-2.20)$ & $(-3.44)$ & $(-2.30)$ & $(-3.84)$ & $(-2.50)$ \\
\hline \multirow[t]{2}{*}{ Slovenia } & 0.76 & 0.95 & 0.93 & 0.88 & 0.60 & 0.95 & 0.86 & 0.93 \\
\hline & $(-3.37)$ & $(-2.05)$ & $(-2.54)$ & $(-2.86)$ & $(-4.11)$ & $(-1.89)$ & $(-3.72)$ & $(-1.94)$ \\
\hline $\bar{t}$ & -2.90 & -3.87 & -2.79 & -3.08 & -3.21 & -3.95 & -2.99 & -2.60 \\
\hline$\mu$ & -1.53 & -1.54 & -1.52 & -1.54 & -1.53 & -1.53 & -1.52 & -1.53 \\
\hline$\sigma^{2}$ & 0.69 & 0.50 & 0.52 & 0.57 & 0.65 & 0.54 & 0.62 & 0.62 \\
\hline$z$-stat. & $-4.96^{* * *}$ & $-10.45^{* * * *}$ & $-5.25^{* * *}$ & $-6.43^{* * *}$ & $-6.23^{* * *}$ & $-10.42^{* * *}$ & $-5.56^{* * *}$ & $-4.29^{* * *}$ \\
\hline
\end{tabular}

Notes: 1. NA means data not available. 2. The reported coefficient values are the convergence rates, or simply one plus the autoregressive coefficients. 3 . The $t$-statistics, reported below the coefficients, are negative since they correspond to the autoregressive coefficients of ADF estimations. 4. The $\bar{t}$ is the arithmetic mean of the individual $t$-statistics. 5. The $z$-statistics are derived using the 95\% critical values of $\mu$ and $\sigma^{2}$ along with Eq. (2).

*** Significance level of $1 \%$.

Hadri test results are reported in Table 3. Concentrating on the Newey and West (1994) and Andrews and Monahan (1992) estimates of long run variance, we reject the null hypothesis of stationarity only in half of the series. Hence, for especially in price series, we cannot reject the hypothesis that all countries are converging to EU standards. Under the mean-stationarity (MS) specification, we find real and nominal convergence, especially towards Germany, for some of the countries, which is consistent with the IPS results in Table 2. However, if the trend-stationarity (TS) assumption is imposed, we fail to reject stationarity in both price series to both benchmarks, although the other convergence results persist. Hence, price-level convergence is due to the rapid decline in inflation rates, generating a negative inflation trend for every country. The interpretation of these results lies in the fact that both statistics average individual values across $N$ so that the outliers in each test, i.e., those that are strongly stationary for IPS or strongly non-stationary for Hadri, are the determining factors. More importantly, the results indicate that inferences on convergence are sensitive to the econometric methodology employed. Therefore, we turn to the 
Table 3

Hadri tests and series-specific critical values

\begin{tabular}{|c|c|c|c|c|c|c|c|c|}
\hline & \multicolumn{4}{|c|}{ Germany } & \multicolumn{4}{|c|}{ Greece } \\
\hline & $\begin{array}{l}\text { Industrial } \\
\text { production }\end{array}$ & $\begin{array}{l}\text { CPI } \\
\text { inflation }\end{array}$ & $\begin{array}{l}\text { PPI } \\
\text { inflation }\end{array}$ & Spread & $\begin{array}{l}\text { Industrial } \\
\text { production }\end{array}$ & $\begin{array}{l}\text { CPI } \\
\text { inflation }\end{array}$ & $\begin{array}{l}\text { PPI } \\
\text { inflation }\end{array}$ & Spread \\
\hline \multicolumn{9}{|c|}{ Stationary around a deterministic mean } \\
\hline $\mathrm{A} \& \mathrm{M}$ & $8.16^{* *}$ & $5.68^{* *}$ & $4.39^{* *}$ & $5.05^{* *}$ & $3.92^{* *}$ & $6.00^{* *}$ & 1.59 & $2.75^{*}$ \\
\hline $\mathrm{N} \& \mathrm{~W}$ & $6.60^{* *}$ & $4.17^{* *}$ & $4.65^{* *}$ & $4.19^{* *}$ & $2.95^{* *}$ & $4.33^{* *}$ & 1.72 & 2.21 \\
\hline Critical (A\&M) & 1.91 & 3.23 & 3.00 & 2.53 & 2.11 & 3.22 & 2.29 & 2.81 \\
\hline Critical (N\&W) & 1.81 & 3.25 & 2.90 & 2.46 & 2.01 & 3.12 & 2.13 & 2.75 \\
\hline \multicolumn{9}{|c|}{ Stationary around a deterministic trend } \\
\hline $\mathrm{A} \& \mathrm{M}$ & $10.02^{* *}$ & -1.05 & -0.49 & $6.03^{* *}$ & $5.81^{* *}$ & 0.55 & -0.92 & $2.87^{* *}$ \\
\hline $\mathrm{N} \& \mathrm{~W}$ & $9.11^{* *}$ & -1.71 & -0.19 & $5.31^{* *}$ & $5.01^{* *}$ & 0.19 & -0.84 & $2.60^{* * *}$ \\
\hline Critical (A\&M) & 1.84 & 3.17 & 2.82 & 2.27 & 1.79 & 3.23 & 2.09 & 2.56 \\
\hline Critical (N\&W) & 1.77 & 3.08 & 2.78 & 2.16 & 1.75 & 3.02 & 1.97 & 2.39 \\
\hline
\end{tabular}

Notes: 1 . The abbreviation A\&M refers to the normalized average $L M$ statistic obtained using the Andrews and Monahan (1992) long-run variance estimator while the abbreviation N\&W refers to the Newey and West (1994) estimator. 2. We reject the null hypothesis at $5 \%$ if the one-sided statistic is greater than the reported critical values. Sample sizes vary due to the truncation necessary to supply a balanced panel.

* Significance level of $10 \%$.

** Idem. 5\%.

SUR-ADF methodology to derive series-specific information on convergence. Although these tests have lower power than the above two tests, the methodology allows us to draw country-specific implications.

Table 4 reports the SUR-ADF results; the significance levels for these results are determined by comparing the $t$ values reported in the 2 nd row with the critical values reported in the 3rd row that are derived from Monte Carlo simulations. ${ }^{8}$ The results indicate strong real convergence to Germany and even slightly stronger towards Greece. Out of nine relevant countries, we find real convergence for seven of them towards Germany and eight towards Greece. Only, Hungary does not converge to either Germany or Greece; Lithuania does not convergence to Germany. Therefore, the results confirm the strong real stochastic convergence we obtained using the two other methods. However, the remaining results in Table 4 support less nominal convergence than either the Hadri or IPS tests. Out of ten countries, we find four cases of CPI inflation convergence towards Germany, i.e., Cyprus, Estonia, Latvia, and Malta, and three towards Greece, namely, Estonia, Latvia and Lithuania. For the PPI, we find only two cases of convergence towards Germany, i.e., Lithuania and Slovak Republic, and only Lithuania converges towards Greece. These results indicate that CEE5 does not convergence to the EU inflation levels. Finally, for monetary policy convergence measured by interest rate spreads, only Lithuania is converging toward Germany and three countries, i.e., Latvia, Lithuania and Poland, are converging toward Greece. Again, the Baltic countries show more convergence than the CCE5, Cyprus, and Malta.

\footnotetext{
8 We use the cross-correlation matrix of each panel and 5000 iterations to derive the SUR-ADF critical values. Breuer et al. (2002) provides a discussion the simulation process.
} 
Table 4

Convergence results: SUR-ADF method

\begin{tabular}{|c|c|c|c|c|c|c|c|c|}
\hline & \multicolumn{4}{|c|}{ Germany } & \multicolumn{4}{|c|}{ Greece } \\
\hline & $\begin{array}{l}\text { Industrial } \\
\text { production }\end{array}$ & $\begin{array}{l}\text { CPI } \\
\text { inflation }\end{array}$ & $\begin{array}{l}\text { PPI } \\
\text { inflation }\end{array}$ & Spread & $\begin{array}{l}\text { Industrial } \\
\text { production }\end{array}$ & $\begin{array}{l}\text { CPI } \\
\text { inflation }\end{array}$ & $\begin{array}{l}\text { PPI } \\
\text { inflation }\end{array}$ & Spread \\
\hline \multirow[t]{3}{*}{ Cyprus } & $0.72^{*}$ & $0.74^{* *}$ & 0.87 & 0.91 & $0.72^{*}$ & 0.91 & 0.93 & 0.97 \\
\hline & $(-3.13)$ & $(-3.81)$ & $(-2.72)$ & $(-2.37)$ & $(-3.13)$ & $(-3.35)$ & $(-2.81)$ & $(-1.99)$ \\
\hline & $(-3.55)$ & $(-3.50)$ & $(-3.66)$ & $(-3.79)$ & $(-3.47)$ & $(-4.92)$ & $(-3.96)$ & $(-4.79)$ \\
\hline \multirow[t]{3}{*}{ Czech Rep. } & $0.79^{*}$ & 0.97 & 0.96 & 0.94 & $0.83^{* *}$ & 0.96 & 0.96 & 0.96 \\
\hline & $(-3.58)$ & $(-1.81)$ & $(-1.76)$ & $(-2.05)$ & $(-4.05)$ & $(-1.57)$ & $(-1.42)$ & $(-1.50)$ \\
\hline & $(-3.99)$ & $-4.35)$ & $(-4.32)$ & $(-4.31)$ & $(-4.01)$ & $(-3.93)$ & $(-3.93)$ & $(-4.64)$ \\
\hline \multirow[t]{3}{*}{ Estonia } & $0.78^{*}$ & $0.94^{*}$ & 0.95 & 0.91 & $0.71^{*}$ & $0.92^{* *}$ & 0.92 & 0.87 \\
\hline & $(-3.56)$ & $(-5.12)$ & $(-3.27)$ & $(-2.57)$ & $(-3.92)$ & $(-6.05)$ & $(-3.76)$ & $(-3.19)$ \\
\hline & $(-3.75)$ & $(-5.24)$ & $(-5.18)$ & $(-4.52)$ & $(-3.99)$ & $(-5.37)$ & $(-4.99)$ & $(-4.11)$ \\
\hline \multirow[t]{3}{*}{ Hungary } & 0.83 & 0.99 & 0.99 & 0.95 & 0.75 & 0.99 & 0.99 & 0.93 \\
\hline & $(-2.03)$ & $(-1.01)$ & $(-0.95)$ & $(-2.88)$ & $(-2.09)$ & $(-1.13)$ & $(-0.72)$ & $(-3.18)$ \\
\hline & $(-3.39)$ & $-4.85)$ & $(-4.80)$ & $(-4.52)$ & $(-3.63)$ & $(-4.61)$ & $(-4.67)$ & $(-4.37)$ \\
\hline \multirow[t]{3}{*}{ Latvia } & $0.77^{* *}$ & $0.85^{* *}$ & 0.96 & 0.87 & $0.80^{* *}$ & $0.80^{* *}$ & 0.97 & $0.85^{*}$ \\
\hline & $(-4.51)$ & $(-7.77)$ & $(-2.33)$ & $(-3.42)$ & $(-4.54)$ & $(-8.69)$ & $(-1.55)$ & $(-3.77)$ \\
\hline & $(-3.85)$ & $(-5.18)$ & $(-4.14)$ & $(-4.39)$ & $(-3.99)$ & $(-5.34)$ & $(-3.85)$ & $(-4.24)$ \\
\hline \multirow[t]{3}{*}{ Lithuania } & 0.82 & 0.95 & $0.95^{* *}$ & $0.78^{*}$ & $0.84^{*}$ & $0.93^{*}$ & $0.94^{* *}$ & $0.74^{* *}$ \\
\hline & $(-3.12)$ & $(-4.17)$ & $(-5.84)$ & $(-3.23)$ & $(-3.33)$ & $(-4.66)$ & $(-6.43)$ & $(-3.96)$ \\
\hline & $(-3.61)$ & $(-4.76)$ & $(-4.34)$ & $(-3.44)$ & $(-3.55)$ & $(-4.78)$ & $(-3.90)$ & $(-3.42)$ \\
\hline \multirow[t]{3}{*}{ Malta } & & $0.77^{* * *}$ & & 0.94 & & 0.92 & & 0.92 \\
\hline & & $(-4.12)$ & & $(-1.67)$ & & $(-3.60)$ & & $(-2.05)$ \\
\hline & & $(-3.62)$ & & $(-3.98)$ & & $(-4.56)$ & & $(-4.32)$ \\
\hline \multirow[t]{3}{*}{ Poland } & $0.82^{* *}$ & 0.98 & 0.98 & 0.90 & $0.83^{* *}$ & 0.98 & 0.98 & $0.86^{*}$ \\
\hline & $(-3.79)$ & $(-2.85)$ & $(-1.97)$ & $(-2.10)$ & $(-4.58)$ & $(-2.43)$ & $(-2.07)$ & $(-4.04)$ \\
\hline & $(-3.58)$ & $(-5.45)$ & $(-4.93)$ & $(-3.67)$ & $(-3.77)$ & $(-5.24)$ & $(-4.44)$ & $(-4.22)$ \\
\hline \multirow[t]{3}{*}{ Slovak Rep. } & $0.78^{*}$ & 0.92 & $0.76^{* *}$ & 0.82 & $0.79^{*}$ & 0.93 & 0.85 & $0.76^{* *}$ \\
\hline & $(-3.52)$ & $(-2.76)$ & $(-4.06)$ & $(-2.55)$ & $(-3.75)$ & $(-2.68)$ & $(-2.66)$ & $(-3.96)$ \\
\hline & $(-3.85)$ & $(-3.72)$ & $(-3.64)$ & $(-3.67)$ & $(-3.93)$ & $(-3.98)$ & $(-3.71)$ & $(-3.73)$ \\
\hline \multirow[t]{3}{*}{ Slovenia } & $0.61^{* *}$ & 0.96 & 0.97 & 0.97 & $0.74^{* *}$ & 0.94 & 0.91 & 0.93 \\
\hline & $(-5.18)$ & $(-2.59)$ & $(-1.65)$ & $(-1.71)$ & $(-5.02)$ & $(-2.84)$ & $(-3.48)$ & $(-2.86)$ \\
\hline & $(-3.48)$ & $(-4.95)$ & $(-4.23)$ & $(-4.75)$ & $(-3.75)$ & $(-4.40)$ & $(-3.97)$ & $(-4.27)$ \\
\hline
\end{tabular}

Notes: The first rows display the autoregressive (AR) coefficients while the second and third rows show the individual $t$-statistics and the $95 \%$ critical values

* Significance level of $10 \%$.

** Idem. 5\%.

In summary, the results in Table 4 indicate only weak nominal convergence. The Baltic states show the most nominal convergence, while Poland and the Slovak Republic exhibit some convergence in contrast to the other CEE5 countries. Cyprus and Malta show only CPI convergence. The lack of price-level convergence may be explained by strong productivity shocks creating Balassa-Samuelson (BS) effects, which indicate that the overall inflation rate will be higher in the new EU members than in the Euro-zone countries at a given exchange rate. Égert (2002) and Égert et al. (2003) find significant BS effects in Central and Eastern Europe. In addition, CPI shocks contain significant fiscal shocks so that the lack of CPI convergence in the CEE5 countries may reflect an overall concern 
about public debt and deficits. According to Berger et al. (2004), fiscal performance has been deteriorating in Central European countries but improving in the Baltic states. This decline in the fundamental fiscal position is attributed to political factors, such as the recent elections and the stronger bargaining position of Central European countries resulting from their membership in major international institutions such as NATO and the WTO. Recent fiscal conditions in the CEE5 countries indicate weak fiscal responsibility. In December 2003, the fiscal deficit as percent of GDP reached 6.6 percent in the Czech Republic, 5.9 percent in Hungary, and 4.1 percent in Poland. The corresponding deficit figures for Latvia and Lithuania were only 1.8 and 1.7 percent, respectively, while Estonia had a surplus of 2.6 percent. Similarly, the ratio of fiscal debt to GDP in December 2003 in the Czech Republic, Hungary and Poland was 37.6, 59, and 45.4 percent, respectively. The corresponding figures for Estonia, Latvia and Lithuania were 5.8, 15.6 and 21.9 percent, respectively. Buiter (2004) argues that achieving fiscal sustainability is not only a necessary condition but also a sufficient one for full EMU membership. Our results indicate this condition is not met in the CEE5 but has been achieved by the Baltic states.

Since our interest rates spread result captures the efficiency of the financial markets and reflects institutional aspects of the economies' countries, those countries having institutions that are better able to handle asymmetric information problems in financial markets are likely to converge faster. Our results suggest that the Baltic countries may be more developed institutionally than the CEE5 countries. The lack of monetary policy convergence in the CEE5 countries can be explained by the relatively more flexible nature of the exchange rate systems in these countries than in the Baltic states. During our sample period, two of the Baltic states adopted a currency board regime, while Latvia maintained a hard peg against Special Drawing Rights (SDR). As a result, we expect to find significant nominal convergence for these countries. Finally, our results are consistent with Babetskii et al. (2004) who find that the Baltic states converge more than the other transition countries in their sample and attribute their finding to the exchange rate regimes.

Our methodology allows us to draw implications about the speed of adjustment of converging countries to the Euro-area shocks. Because we focus on conditional stochastic convergence, this test indicates the speed with which these countries return to their own steady state after a common shock. Strong stochastic convergence suggests that Euro-area shocks lead to only transitory deviations from the EU trend. However, if the necessary institutional mechanisms are not in place in the new members, a shock will lead to a deviation from the trend of the core EU countries for lengthy periods. To illustrate the implied adjustment speeds, we compute half-life estimates using the coefficients obtained from the SUR-ADF estimations and report them in Table 5. ${ }^{9}$ Regarding real convergence, a return to the steady state takes from four to eight months for these converging countries. However, strong price-level shocks are more persistent in Estonia and Lithuania, reaching 27 months. Alternatively, the adjustment to price shocks in the converging countries is quicker, taking between four to six months. Finally, the half-life results for the interest rate spread indicate a relatively rapid adjustment to monetary policy shocks, ranging from four to eight

\footnotetext{
${ }^{9}$ Half-lives are calculated as $\ln (0.5) / \ln (\rho)$, where $\rho$ is the AR parameter in Eq. (1).
} 
Table 5

Half-lives for convergent countries

\begin{tabular}{|c|c|c|c|c|c|c|c|c|}
\hline & \multicolumn{4}{|c|}{ Germany } & \multicolumn{4}{|c|}{ Greece } \\
\hline & $\begin{array}{l}\text { Industrial } \\
\text { production }\end{array}$ & $\begin{array}{l}\text { CPI } \\
\text { inflation }\end{array}$ & $\begin{array}{l}\text { PPI } \\
\text { inflation }\end{array}$ & Spread & $\begin{array}{l}\text { Industrial } \\
\text { production }\end{array}$ & $\begin{array}{l}\text { CPI } \\
\text { inflation }\end{array}$ & $\begin{array}{l}\text { PPI } \\
\text { inflation }\end{array}$ & Spread \\
\hline Cyprus & 2.1 & 2.3 & & & 2.1 & & & \\
\hline Czech Rep. & 2.9 & & & & 3.7 & & & \\
\hline $\begin{array}{l}\text { Estonia } \\
\text { Hungary }\end{array}$ & 2.8 & 11.2 & & & 2.0 & 8.3 & & \\
\hline Latvia & 2.7 & 4.3 & & & 3.1 & 3.1 & & 4.3 \\
\hline Lithuania & & & 13.5 & 2.8 & 4.0 & 9.6 & 11.2 & 4.3 \\
\hline Malta & & 2.7 & & & & & & 2.3 \\
\hline Poland & 3.5 & & & & 3.7 & & & \\
\hline Slovak Rep. & 2.8 & & 2.5 & & 2.9 & & & 4.6 \\
\hline Slovenia & 1.4 & & & & 2.3 & & & 2.5 \\
\hline
\end{tabular}

Notes: 1. Half-lives are measured in months of convergence to the trend and reported only for the significant coefficients in Table 4 with respect to Germany and Greece. 2 . The values indicate the number of months it would take a deviation from the trend of variables in Greece or Germany to be eliminated.

months. Overall, except for Estonia and Lithuania, the results demonstrate a fast speed of convergence and, thus, strong level of convergence for these countries. The large priceconvergence period for the two Baltic countries may be due to the relatively high inflation rate during the 1990s.

\section{Conclusion}

Using macroeconomic data from January 1993 to December 2003, we test for real and monetary stochastic convergence in the ten recently admitted EU economies. Our findings indicate that these new members have made significant progress in real convergence towards the EU, regardless of whether Germany or Greece is used as the benchmark. Regarding nominal convergence, the Baltic states that pursued hard pegged exchange rate regimes exhibit the strongest convergence. The CEE5 countries show weak convergence towards both Germany and Greece, which may be explained by their lack of fiscal discipline, especially in recent years, and strong Balassa-Samuelson effects. Hence, policymakers in these CEE5 countries should focus on fiscal sustainability and continue to support flexible exchange rates, which can accommodate the negative productivity effects on trade competitiveness. Therefore, the CEE5 countries must not rush to adopt the Euro but rather pursue fiscal sustainability before joining ERM II. Given the growing evidence of strong BalassaSamuelson effects in the CEE5 countries with the resulting inverse impact on price levels, the condition for inflation convergence should be redefined to include a premium to hasten their joining the Euro zone.

Regarding methodology, our results indicate the sensitivity of inferences about convergence to different econometric specifications. More powerful tests, namely Hadri and IPS, have very general null and alternative hypotheses while country-specific tests have lower power because they take less advantage of pooling the data. Because no single method 
outperforms the others for estimating convergence, the robustness of convergence results deserves further scrutiny.

\section{Acknowledgments}

We thank two anonymous referees and Selin Sayek, for their useful comments. The usual disclaimer applies. We are grateful to John Bonin, the Editor, for his editorial comments and suggestions, and to Héléne Bonin, the Managing Editor, for her support and encouragement.

\section{Appendix A}

We have level data from January 1992 to December 2003 for Cyprus, Germany, Greece, Hungary, Poland, and Slovenia. PPI and industrial production data are not available for Malta; therefore, this country is excluded from the panel regressions in those variables. Annual growth rates are obtained by log-differencing the twelve-month lag. Since 1992, level data are missing for the Czech and Slovak Republics, and for most variables in Latvia and Lithuania, we lack one year of observations for the growth data in these countries. PPI data for Latvian and Estonian PPI are missing prior to 1994; hence, we have growth rates only from 1995 for these countries. If a change or a break occurred in the IFS data, we obtained data from Statistical Offices, Finance Ministries and the Central Banks in the relevant countries and used the growth rates of these datasets to derive the data prior to or after the break.

The simulated critical values are generated using 5000 iterations and the crosscorrelation matrices between the growth rates of the members in the panel. The Choleski factorizations of the cross-correlation matrices are used to generate correlated error series that are cumulated into random walk series. Then IPS, Hadri, and SUR-ADF tests are used on the generated series; the 250th lowest $t$ values from the IPS and SUR-ADF tests and the 250th highest $L M$ statistic from the Hadri test is used to generate $95 \%$ critical values.

\section{References}

Andrews, Donald W.K., Monahan, J. Christopher, 1992. An improved heteroskedasticity and autocorrelation consistent covariance matrix estimator. Econometrica 60, 953-966.

Babetskii, Ian, Boone, Laurence, Maurel, Mathilde, 2004. Exchange rate regimes and shocks asymmetry: the case of the accession countries. Journal of Comparative Economics 32, 212-229.

Backè, Peter, Fidrmuc, Jarko, Reininger, Thomas, Schardax, Franz, 2003. Price dynamics in Central and Eastern European EU accession countries. Emerging Markets Finance and Trade 39, 42-78.

Barro, Robert J, Sala-i-Martin, Xavier X., 1992. Convergence. Journal of Political Economy 100, $223-251$.

Berger, Helge, Kopits, George, Szekély, István, 2004. Fiscal indulgence in Central Europe: Loss of the external anchor? IMF Working Paper WP 04/62.

Bernard, Andrew B, Durlauf, Steven N., 1996. Interpreting tests of the convergence hypothesis. Journal of Econometrics 71, 161-173. 
Boone, Laurence, Maurel, Mathilde, 1998. Economic convergence of the CEECs with the EU. Discussion Paper No. 2018. CEPR, London.

Boone, Laurence, Maurel, Mathilde, 1999. An optimal currency area perspective of the EU enlargement to the CEECs. Discussion Paper No. 2119. CEPR, London.

Brada, Josef C., Kutan, Ali M., 2001. The Convergence of monetary policy between candidate countries and the European Union. Economic Systems 25, 215-231.

Breuer, Janice B., McNown, Robert, Wallace, Myles, 2002. Series-specific unit root tests with panel data. Oxford Bulletin of Economics and Statistics 64, 527-546.

Buiter, Willem H., 2004. The purgatory and beyond: when and how should the accession countries from central and eastern Europe become full members of EMU? Working Paper No. 4342. CEPR, London.

Égert, Balazs, 2002. Estimating the impact of the Balassa-Samuelson effect on inflation and the real exchange rate during the transition. Economic Systems 26, 1-16.

Égert, Balazs, Drine, Imed, Lommatzsch, Kirsten, Rault, Chritophe, 2003. The Balassa-Samuelson effect in Central and Eastern Europe: Myth or reality? Journal of Comparative Economics 31, 552-572.

European Central Bank, 2002. The Eurosystem and the accession process. Position Paper of the Governing Council of the European Central Bank, Frankfurt.

Fidrmuc, Jarko, Korhonen, Iikka, 2003. Similarity of supply and demand shocks between the Euro area and the accession countries. Economic Systems 27, 313-334.

Friedman, Milton, 1992. Do old fallacies ever die? Journal of Economic Literature 30, 2129-2132.

Hadri, Kaddour, 1999. Testing for stationarity in heterogeneous panel data with serially correlated errors. Research Papers in Economics, Finance and Accounting. University of Liverpool.

Hadri, Kaddour, 2000. Testing for stationarity in heterogeneous panel data. Econometrics Journal 3 (2), $148-161$.

Im, Kyung S., Pesaran, M. Hashem, Shin, Yongcheol, 2003. Testing for unit roots in heterogeneous panels. Journal of Econometrics 115 (1), 53-74.

Kočenda, Evžen, 2001. Macroeconomic convergence in transition economies. Journal of Comparative Economics 29, 1-23.

Kutan, Ali, Yigit, Taner, 2004. Nominal and real stochastic convergence of transition economies. Journal of Comparative Economics 32, 23-36.

Levin, Andrew, Lin, Chien-Fu, Chu, Chia-Shang J., 2002. Unit root tests in panel data: Asymptotic and finitesample properties. Journal of Econometrics 108, 1-24.

Maddala, G.S., Wu, Shaowen, 1999. A comparative study of unit root tests with panel data and a new simple test. Oxford Bulletin of Economics and Statistics 61 (Special issue), 631-652.

Newey, Whitney K., West, Kenneth D., 1994. Automatic lag selection in covariance matrix estimation. Review of Economic Studies 61, 631-653.

Quah, Danny, 1992. International patterns of growth: persistence in cross-country disparities. Unpublished manuscript. London School of Economics.

Quah, Danny, 1993. Galton's fallacy and tests of the convergence hypothesis. Scandinavian Journal of Economics 95, 427-443.

Richards, Anthony J., Tersman, Gunnar H.R., 1996. Growth, nontradables, and price convergence in the Baltics. Journal of Comparative Economics 23 (2), 121-145.

Strauss, Jack, Yigit, Taner M., 2003. Shortfalls of panel unit root testing. Economics Letters 81 (3), 309-313. 